\title{
Observations of Small-Scale Secondary Instabilities during the Shoaling of Internal Bores on a Deep-Ocean Slope
}

\author{
FrÉDÉRIC CYR AND HANS VAN HAREN \\ Royal Netherlands Institute for Sea Research (NIOZ), Texel, Netherlands
}

(Manuscript received 27 March 2015, in final form 16 October 2015)

\begin{abstract}
The Rockall Bank area, located in the northeast Atlantic Ocean, is a region dominated by topographically trapped diurnal tides. These tides generate up- and downslope displacements that can be locally described as swashing motions on the bank. Using high spatial and time resolution of moored temperature sensors, the transition toward the upslope flow (cooling phase) is described as a rapid upslope-propagating bore, likely generated by breaking trapped internal waves. Buoyant anomalies are found during the bore propagation, likely resulting from small-scale instabilities. The imbalance between the rate of disappearance of available potential energy and the dissipation rate of turbulent kinetic energy suggests that these instabilities are growing (i.e., young) and have high mixing potential.
\end{abstract}

\section{Introduction}

Internal wave turbulence over underwater topography is generally thought to be the main contributor to the global ocean mixing budget (Armi 1978; Polzin et al. 1997; Ledwell et al. 2000; Jayne and St. Laurent 2001; St. Laurent and Garrett 2002; Wunsch and Ferrari 2004; Waterhouse et al. 2014). In the deep ocean, internal tides, a specific class of internal waves that result from the interaction of barotropic tidal motions with the topography, are the dominant wave-mixing mechanism. To better understand where and when such waves release their energy into mixing in the world's oceans, numerous studies have focused on the interaction of internal tides with the topography (e.g., St. Laurent and Garrett 2002; Rudnick et al. 2003; Garrett and Kunze 2007).

Taking advantage of the high spatial and temporal resolution of moored temperature sensors arrays developed at the Royal Netherlands Institute for Sea Research (NIOZ; van Haren et al. 2009), this study focuses on mixing by trapped internal waves above a deep-sea sloping topography. The region under the scope of this study is the Rockall Bank area (Fig. 1), which is known

Corresponding author address: Frédéric Cyr, Royal Netherlands Institute for Sea Research (NIOZ), P.O. Box 59, 1790 AB den Burg, Texel, Netherlands.

E-mail: frederic.cyr@nioz.nl for hosting resonant topographically trapped diurnal tides that propagate anticyclonically around the bank (Huthnance 1974; Pingree and Griffiths 1984; White et al. 2007). Internal wave motions presented here are thus not free to propagate in tidal rays, and their energy exponentially decreases with increasing distance from the topography. While a previous study by our team described the trapped internal waves as fronts occurring at a diurnal frequency (van Haren et al. 2014), the present study focuses on the energy release and the turbulence modulation on a diurnal cycle. More precisely, this study aims to show that 1) diurnal internal swash over a coral mound in the Rockall Bank area can generate energetic upslopepropagating borelike structures; 2) growing secondary instabilities (i.e., young turbulence) are associated with such bore propagation; and 3) under some circumstances, these instabilities may be highly efficient in mixing the waters over the sloping seafloor.

\section{Data}

The dataset used in this study is identical to that described in van Haren et al. (2014) and briefly summarized here. It consists of a moored array of 119 NIOZ-4 temperature sensors, sampling the water column at $1 \mathrm{~Hz}$ from 7 to $126 \mathrm{~m}$ above the bottom. The mooring was deployed for 9 days (8-16 October 2012) in the Logachev area, on the southeast slopes of Rockall Bank, in a water depth of $919 \mathrm{~m}$ and at geographic position $55^{\circ} 28.947^{\prime} \mathrm{N}$, 


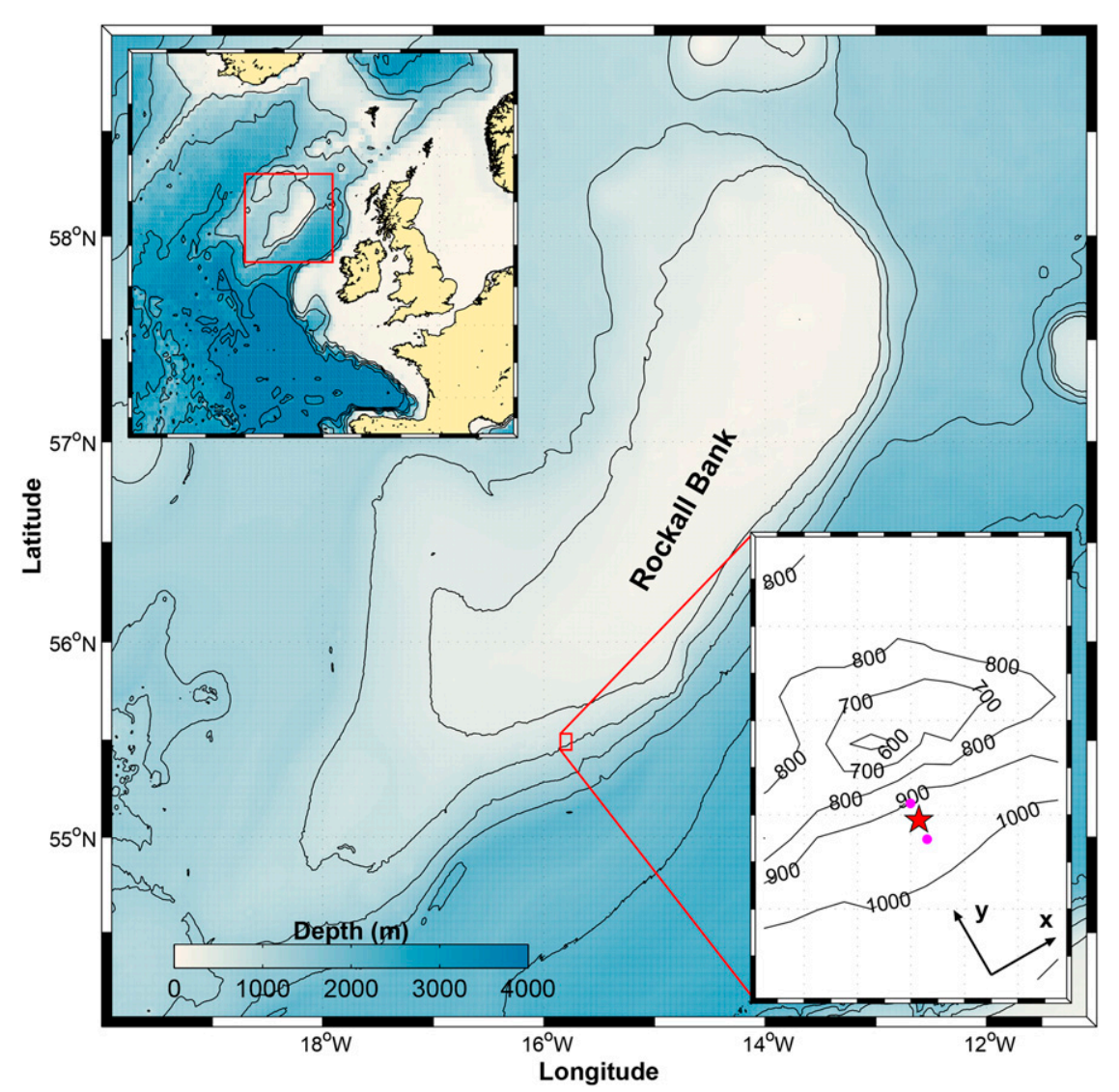

FIG. 1. Rockall Bank area (main figure) located about $400 \mathrm{~km}$ northwest of Ireland in the northeast Atlantic Ocean (upper inset). The study area is located in the Logachev cold water coral mounds area (bottom inset) on the southern slopes of Rockall Bank. The mooring location (red star) and the CTD stations (magenta dots) are indicated.

$15^{\circ} 47.852^{\prime} \mathrm{W}$ (Fig. 1). The sensors were vertically separated in $0.6-\mathrm{m}$ intervals in the lower $30 \mathrm{~m}$ and by $1 \mathrm{~m}$ in the upper $90 \mathrm{~m}$. Sensors were synchronized by induction every $4 \mathrm{~h}$ so that the clock mismatch is less than $0.02 \mathrm{~s}$. Among the original number of sensors deployed (140), 21 were lost upon recovery. The top floatation of the mooring, located at $129 \mathrm{~m}$ above bottom, was also equipped with a downward-looking 75-kHz Teledyne-RDI acoustic Doppler current profiler (ADCP). The ADCP was erroneously set up at a too low sampling rate of one time ensemble every $22.5 \mathrm{~min}$ (nine equally spaced pings per ensemble). The sloping topography near the mooring has an angle of about $s \approx 20 \%$.

Conductivity-temperature-depth (CTD) casts were realized about $400 \mathrm{~m}$ upslope and downslope of the mooring site after the mooring recovery (two magenta dots in Fig. 1). The data are used to establish a relationship between temperature and density. The nine casts were dispersed in time so they span most of a diurnal cycle. The relation between potential temperature $\theta_{0}$ and the density anomaly referenced to $1000 \mathrm{~m} \sigma_{1}$ is approximated by a third-order polynomial of the form $\sigma_{1}=a_{3} \theta_{0}^{3}+a_{2} \theta_{0}^{2}+a_{1} \theta_{0}+a_{0}$ between $[6.5,9]^{\circ} \mathrm{C}$ (Fig. 2a), a range chosen so it represents more than $99 \%$ of the temperature measurements during the deployment. Coefficients $a_{0}$ to $a_{3}$ were calculated in a least squares sense and are provided in Table 1 . For $98 \%$ of the points used, the error between the fit and observed density is better than $\pm 0.01 \mathrm{~kg} \mathrm{~m}^{-3}$, with a standard deviation of $0.003 \mathrm{~kg} \mathrm{~m}^{-3}$ (Fig. 2b). This relatively tight relationship was used to infer density from the moored temperature sensors.

\section{Thorpe reordering, available potential energy, and the age of turbulence}

Individual profiles obtained from the moored sensors every $1 \mathrm{~s}$ were sorted into monotonic stable density profiles from which the Thorpe displacements $d$ and Thorpe scale $L_{T}=\operatorname{rms}(d)$ were computed (Thorpe 1977). Note that the Thorpe scale was calculated as the root-mean-square (rms) of the displacements over the 

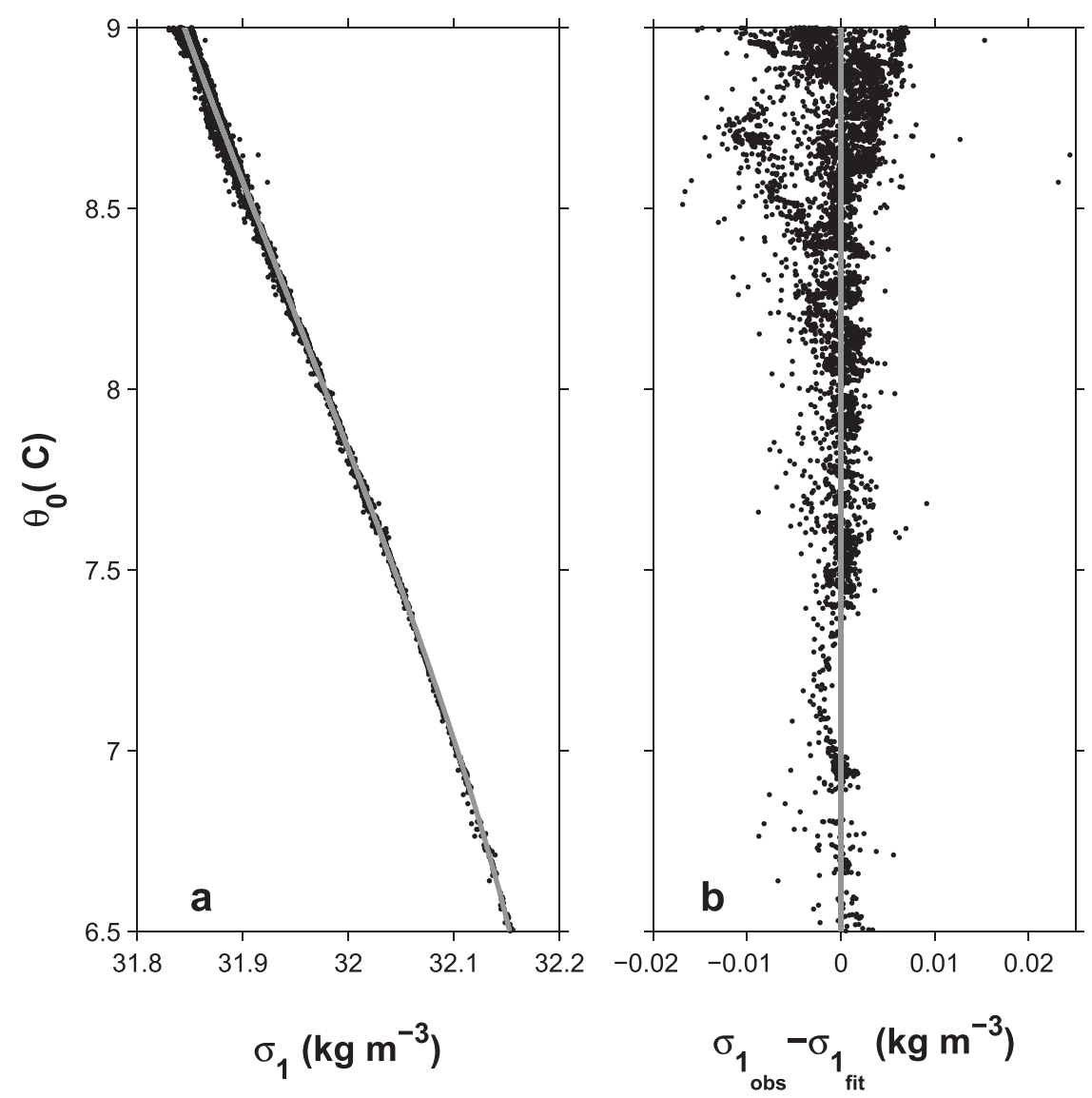

FIG. 2. Temperature-density relationship from nine CTD casts at two stations identified by magenta dots in Fig. 1. (a) Potential temperature referenced to the surface $\theta_{0}$ and density anomaly referenced to $1000 \mathrm{~m} \sigma_{1}$ scatterplot (black dots) and a third-order polynomial fit $\sigma_{1}=a_{3} \theta_{0}^{3}+a_{2} \theta_{0}^{2}+a_{1} \theta_{0}+a_{0}$ (gray line). Coefficients of the fit are given in Table 1 . (b) Difference between observed density anomaly and the third-order fit as a function of potential temperature (black dots). The gray vertical line is the zero difference.

range of temperature sensors and not over single overturns, since overturns are sometimes difficult to isolate in the observations and often extend above the portion of the water column spanned by the mooring. Assuming a relationship between the Thorpe scale and the Ozmidov scale $L_{O}=0.8 L_{T}$ (Dillon 1982), the dissipation rates $\varepsilon$ of TKE was estimated:

$$
\varepsilon=0.64 L_{T}^{2} N^{3},
$$

where $N=\left[-\left(g / \rho_{0}\right)\left(\partial \sigma_{1} / \partial z\right)\right]^{1 / 2}$ is the buoyancy frequency averaged over each individual mooring profile, and $\rho_{0}=1026 \mathrm{~kg} \mathrm{~m}^{-3}$ is a constant reference density. Note that this definition for $N$ (averaged over the depth span of the mooring) is different from the original formulation that uses overturn-averaged $N$ (e.g., Dillon 1982). The present approach is, however, based on a reasonable scale for the largest overturn for this portion of the water column. The measured stratification is thus representative of the near-bottom region, which is also small compared to the full water depth (about $100 \mathrm{~m}$ compared with a total depth of $920 \mathrm{~m}$ ). This approach is more or less similar to some direct numerical simulation (DNS) studies using Thorpe reordering on a fixed domain rather than on single overturns (e.g., Mater et al. 2013).

By differencing the potential energy contained in the raw and reordered density profiles, it is also possible to

TABLE 1. Coefficients for the third-order fit between potential temperature and density anomaly referred to $1000 \mathrm{~m}$ (thin gray line in Fig. 2a). Uncertainties on the mean values are the bootstrap $95 \%$ confidence intervals.

\begin{tabular}{lc}
\hline \hline$\sigma_{1}=a_{3} \theta_{0}^{3}+a_{2} \theta_{0}^{2}+a_{1} \theta_{0}+a_{0}$ & \\
\hline$a_{3}\left(\mathrm{~kg} \mathrm{~m}^{-3}{ }^{\circ} \mathrm{C}^{-3}\right)$ & $0.005 \pm 0.001$ \\
$a_{2}\left(\mathrm{~kg} \mathrm{~m}^{-3}{ }^{\circ} \mathrm{C}^{-2}\right)$ & $-0.14 \pm 0.01$ \\
$a_{1}\left(\mathrm{~kg} \mathrm{~m}^{-3}{ }^{\circ} \mathrm{C}^{-1}\right)$ & $1.0 \pm 0.1$ \\
$a_{0}\left(\mathrm{~kg} \mathrm{~m}^{-3}\right)$ & $29.8 \pm 0.1$ \\
\hline
\end{tabular}


calculate the available potential energy stored in the density fluctuations (APEF). The vertical average of the APEF $(\xi)$ for each 1-s profile was thus calculated using (Dillon 1984; Crawford 1986; Dillon and Park 1987)

$$
\xi=\frac{1}{D} \frac{g}{\rho_{0}} \int_{0}^{D} \sigma_{1}^{\prime} z d z,
$$

where $g=9.81 \mathrm{~m} \mathrm{~s}^{-2}$ is the gravitational acceleration, and $\sigma_{1}^{\prime}(z)=\sigma_{1}(z)-\widetilde{\sigma}_{1}(z)$ is the density fluctuation between the raw $\sigma_{1}$ and sorted $\widetilde{\sigma}_{1}$ density anomaly profiles over the depth spanned by the mooring $(D=120 \mathrm{~m})$.

To better compare its evolution between patches, we normalize $\xi$ by multiplying by the profile-averaged buoyancy frequency. This also allows a direct comparison with $\varepsilon$ since we then obtain a quantity with the same units $\left(\mathrm{m}^{2} \mathrm{~s}^{-3}\right)$ :

$$
J_{b}^{*}=\xi N
$$

We shall call this quantity a potential buoyancy flux because it equals the buoyancy flux $J_{b}$ under certain hypotheses, that is, if the turbulence is in a steady state and if the APEF is completely released into irreversible diapycnal mixing in a relevant time scale for turbulence. Here, this time scale is $\tau \approx 1 / N$. This traditional method for estimating the buoyancy fluxes from the finescale structure has been popularized by Dillon (1984), Crawford (1986), Dillon and Park (1987), Galbraith (1992), and Wijesekera et al. (1993). Because a nonnegligible part of the potential energy may not be released into mixing (the reversible part), $J_{b}^{*}$ is likely an upper bound for the buoyancy flux. However, it is thought that the reversible APEF generally tend to be important only in the preturbulent (low Reynolds number) phase of the flow (Smyth et al. 2001). As shown later, measurements presented in this study are generally realized at relatively high Reynolds numbers $[\mathrm{Re} \sim$ $O\left(10^{7}\right)$ ], which tend to minimize this problem.

Smyth et al. (2001) also suggested that the efficiency of mixing (given by the flux coefficient $\Gamma=J_{b} / \varepsilon$ ) varies with the evolution of a turbulent event. In their numerical study, turbulence was triggered by shear instabilities (Kelvin-Helmholtz billows) and its evolution (its age) was monitored by the ratio $R_{O T}=L_{O} / L_{T}$ (see also Dillon 1982; Wijesekera et al. 1993; Seim and Gregg 1994; Wijesekera and Dillon 1997). For such mixing mechanism, $\Gamma$ was found high in the early stages of the evolution toward turbulence (e.g., maximum during the breaking of the billows) and evolved in time toward an asymptotic value of $\Gamma \sim 0.2$.

Very recently, the link between $R_{O T}$ and the evolution of turbulence was also explored for convective instabilities (Chalamalla and Sarkar 2015; Mater et al. 2015). Again, the authors found larger $R_{O T}$ for younger turbulence (more potential energy) but also concluded that on average $\left\langle R_{O T}\right\rangle \sim O(1)$, where \langle\rangle represent some carefully chosen ensemble average. Note that the original idea of $L_{O} \sim L_{T}$ (Thorpe 1977; Dillon 1982) also implied that this scaling was valid in an average sense [see, e.g., Fig. 9 in Dillon (1982), where the dispersion in the scatterplot spans at least one order of magnitude]. When the number of measurements are sufficient, successful comparison between $L_{T}$ and $L_{O}$ was also verified in many subsequent studies (e.g., Stillinger et al. 1983; Itsweire et al. 1986; Crawford 1986; Galbraith and Kelley 1996; Stansfield et al. 2001; Wesson and Gregg 1994; Ferron et al. 1998). In this regard, the evolution of $R_{O T}$ with the age of turbulence is not inconsistent with the assumption made here (i.e., $L_{O}=0.8 L_{T}$ ) because of the averaging made afterward [e.g., $\langle\varepsilon\rangle]$. In this study, \langle\rangle represents an average window that is larger than or equal to the mean buoyancy period over the mooring deployment (40 min).

While we directly measure $L_{T}$, we do not have an independent measure of $L_{O}$ and are thus unable to estimate $R_{O T}$. However, we suggest that the ratio $\gamma=\left\langle J_{b}^{*}\right\rangle /\langle\varepsilon\rangle$ is informative on the nature of turbulent mixing processes or on the state of their development (their age). This is because this nondimensional ratio, which we call "mixing potential" in the rest of the study, gives the imbalance between the TKE dissipation rate and the rate at which the potential energy for mixing is withdrawn from the water column. Using $\gamma$ as an indicator of the age of turbulence is more or less using one result of Smyth et al. (2001), that is, $\Gamma$ evolves with the age of turbulence, under the assumption that $\gamma$ scales with $\Gamma$. This assumption will be explored below.

\section{Observations}

\section{a. Average diurnal tidal cycle}

The entire dataset was phase averaged in order to highlight the evolution of the water column properties and mixing variables over a diurnal tidal cycle (Fig. 3). For simplicity, the diurnal cycle is defined here as $\phi \in[-0.5,0.5]$ day $( \pm 12 \mathrm{~h})$, with $\phi=0$ corresponding to the maximum upslope velocities. The phase-averaged temperature (Fig. 3a) shows cold water rising from below the mooring roughly for $\phi \in[-0.2,0.2]$ day and warm water lowering from above the mooring for the remaining of the tidal cycle. As also highlighted in van Haren et al. (2014), the cooling (upslope) phase is shorter than the warming (downslope) phase as suggested by the steeper slope of the isotherms in the 


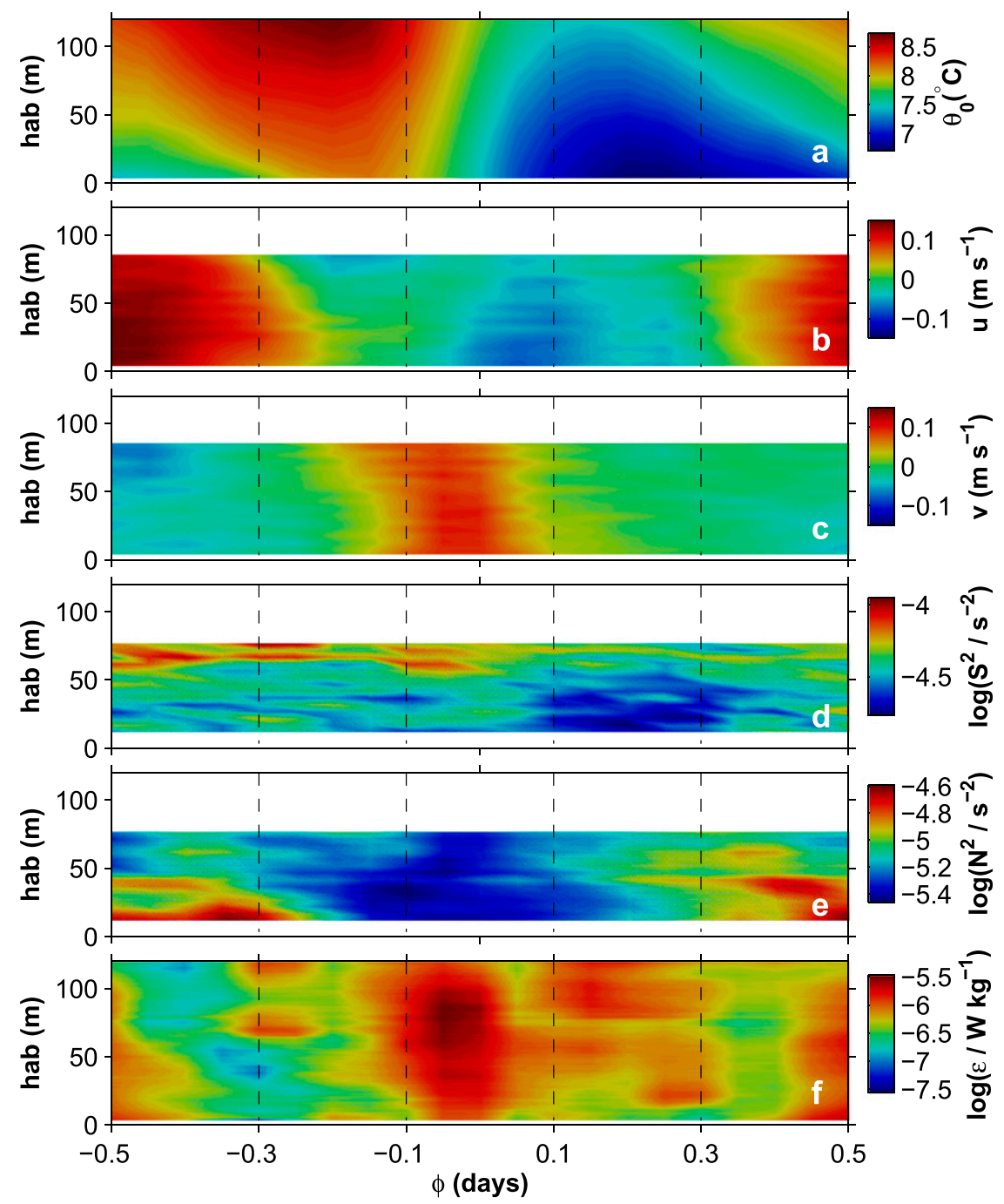

FIG. 3. Diurnal phase-averaged dataset as a function of the hab and relative to the phase of the maximum cross-slope currents $(\phi=0$ day), calculated from vertically averaged and lowpass filtered at 1 cycle per day (cpd) currents in the $y$ axis (see Fig. 1, lower inset). For each quantity listed below, the vertical phase average was calculated in 0.05-day intervals and contour plots were obtained by linear interpolation between points. (a) Potential temperature. (b) Along-slope velocities. (c) Cross-slope velocities. (d) Shear squared. (e) Buoyancy frequency squared. (f) Dissipation rate of TKE.

$\phi \in[-0.1,0.1]$ day interval. The upward displacements are associated with relatively brief and strong upslope currents $(v>0$; Fig. 3c) compared to the rest of the cycle.

The averaged vertical shear squared $S^{2}=(\partial u / \partial z)^{2}+$ $(\partial v / \partial z)^{2}$ varies by about one order of magnitude over the depth range measured by the ADCP, with the highest values in the upper portion of the mooring (Fig. 3d). At a given depth, shear values do not vary much over the diurnal cycle, except for a slight decrease around the reversal between upslope and downslope motions $(\phi \in$ $[0.1,0.3]$ day). The averaged buoyancy frequency squared $\left(N^{2} ;\right.$ Fig. $\left.3 \mathrm{e}\right)$ varies with the diurnal cycle but by less than an order of magnitude. The lowest stratification is found during the upslope phase and the highest during the downslope phase, with the strongest variations close to the bottom.

It is also during the upslope phase $(\phi \in[-0.1,0.1]$ day) that the dissipation rates of TKE are found at their maximum (Fig. 3f). Other periods of strong dissipation are found at the middle of the downslope phase $(\phi \approx 0.5$ and $\phi \approx-0.5$ day) and, for the upper part of the depth span by the mooring, during the reversal between up- to downslope flows $(\phi \in[0.1,0.3]$ day). Note that to calculate the vertical dependence of the dissipation rate, $L_{T}$ 


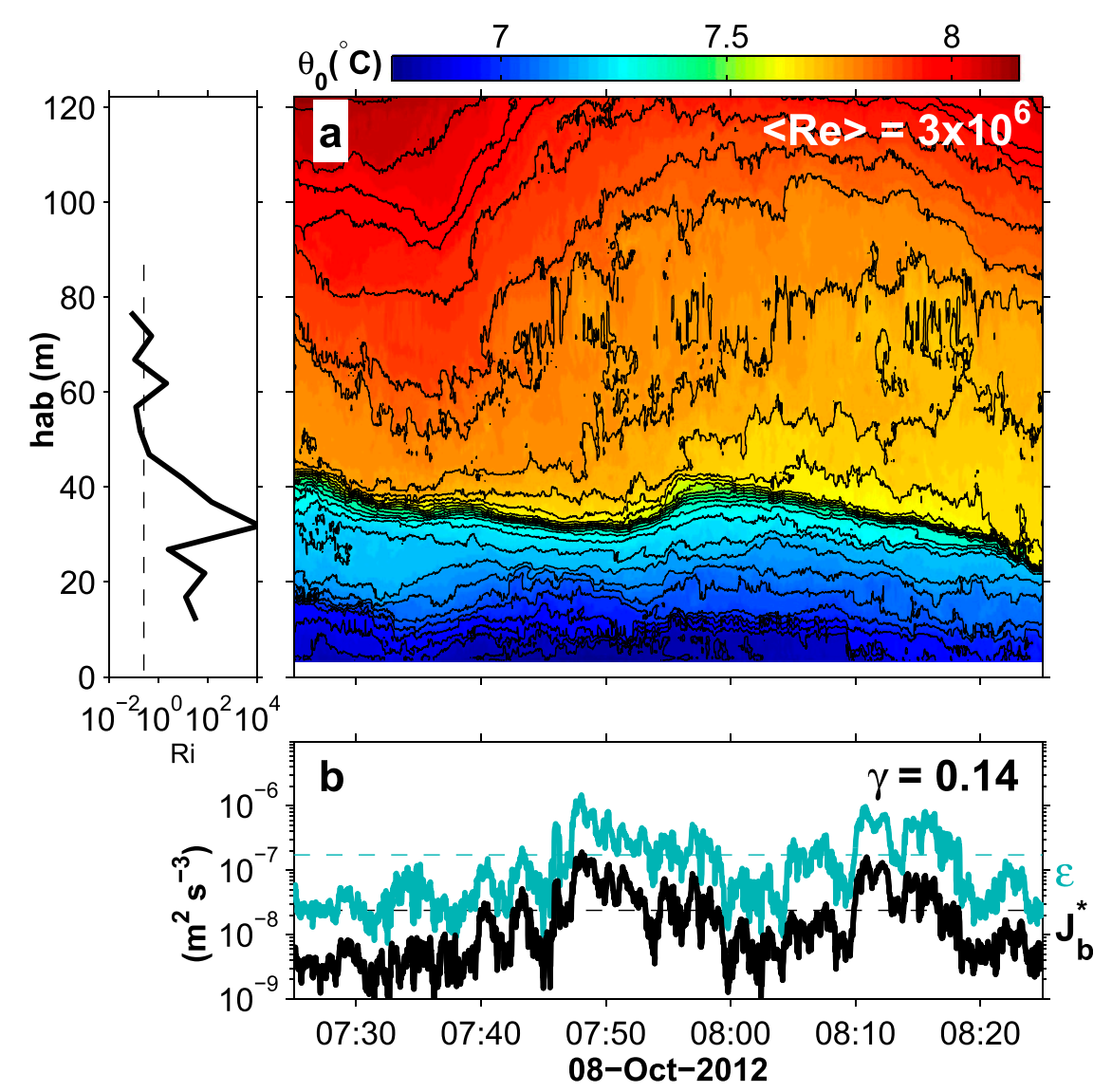

FIG. 4. The 1-h snapshot of the temperature time-depth series and vertically averaged turbulence variables on 10 Oct 2012 between 0725 and 0825 UTC, corresponding to the middle of the downward phase ( $\phi=0.36$ day). (a) Temperature. Isotherms (black lines) are separated by $0.05^{\circ} \mathrm{C}$ increments. The average Reynolds number over this time series is given in the upperright corner. The left panel presents the Richardson number calculated at the ADCP resolution and averaged in time for this 1-h period. (b) Potential buoyancy flux (solid black) and dissipation rate of TKE (solid blue) computed from Eqs. (3) and (1), respectively. Dashed lines indicate the averaged values for the respective parameters $\left\langle J_{b}^{*}\right\rangle$ and $\langle\varepsilon\rangle$, with the average \langle\rangle over the 1-h window. The ratio $\gamma=\left\langle J_{b}^{*}\right\rangle /\langle\varepsilon\rangle$ is presented in the upper right of (b).

was replaced in Eq. (1) by the vertically varying Thorpe displacements $d$ before averaging profiles in the same tidal phase. This method (swapping $L_{T}$ by $d$ and then averaging) was also used in van Haren et al. (2013, 2014). It is verified here that the two methods converge approximately to the same average (to within a factor of 2.5; not shown).

\section{b. Snapshots of the water column in relation with the diurnal cycle}

The 1-s observations of $\theta_{0}, \varepsilon$, and $J_{b}^{*}$ are displayed in snapshots of different phases of the diurnal cycle (Figs. 4, 5, 6). The two first figures are 1-h-long time series and correspond respectively to a period with relatively low turbulence and to an overturning event. The mean gradient Richardson number $\left(\mathrm{Ri}=N^{2} / S^{2}\right.$, left of the upper panel in Figs. 4 and 5) and the Reynolds number ( $\mathrm{Re}$, upper-right corner) are also presented. Here, $\mathrm{Ri}$ is calculated by averaging $N^{2}$ at the resolution of $S^{2}$ (5 m in the vertical and $22.5 \mathrm{~min}$ in time), so that both are at the same scale. Low $\mathrm{Ri}(\mathrm{Ri} \leq 1 / 4$, dashed lines in these panels) suggest favorable conditions for mixing by linear shear instabilities (Miles 1961; Howard 1961). The Reynolds number is calculated as $\operatorname{Re}=\left(U_{\max } d_{\max }\right) / \nu$, where $U_{\max }$ and $d_{\max }$ are the maximum horizontal velocity and the maximum Thorpe displacement over the presented time series, respectively, and $\nu=10^{-6} \mathrm{~m}^{2} \mathrm{~s}^{-1}$ is the kinematic viscosity of seawater, taken constant here.

Figure 4 shows an example of the instantaneous evolution of $\varepsilon$ and $J_{b}^{*}$. During this 1-h period ( $\phi \sim 0.36$ day), they vary mostly parallel. The average ratio $\gamma=\left\langle J_{b}^{*}\right\rangle /\langle\varepsilon\rangle=$ 0.14 is rather low (compared to other phases presented below), indicating some mature state of turbulence (low 


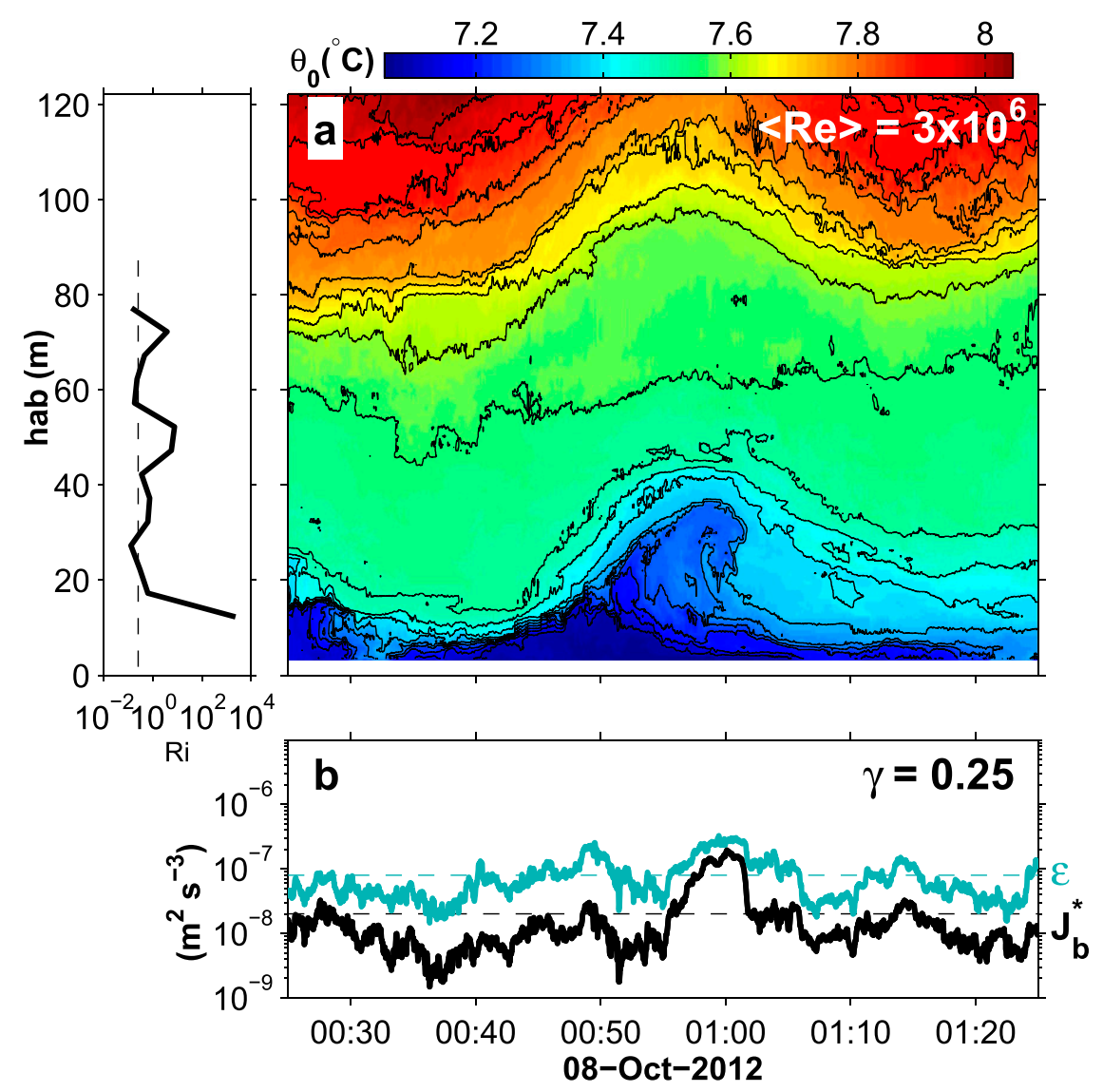

FIG. 5. As in Fig. 4, but on 8 Oct 2012 between 0025 and 0125 UTC, corresponding to the end of the upslope phase ( $\phi \approx 0.15$ day).

mixing potential). This period is characterized by a sharp temperature interface at $\sim 35 \mathrm{~m}$ height above bottom (hab). While shear instabilities may be at work above $\sim 35 \mathrm{~m}$ hab, $\mathrm{Ri}>1 / 4$ below, suggesting less favorable conditions for shear instabilities.

Figure 5 is another 1-h period, presenting an overturning structure about to break. This period corresponds to the end of the upslope phase ( $\phi \sim 0.15$ day). The value of $\mathrm{Ri}<1 / 4$ is observed at about $30 \mathrm{~m}$ hab, the depth of this structure, suggesting that the instability is driven by sheared currents. While $\varepsilon$ oscillates around its average value of $\sim 10^{-7} \mathrm{~W} \mathrm{~kg}^{-1}, J_{b}^{*}$ increases by an order of magnitude above the mean value exactly when the breaking structure is passing the mooring (Fig. 5b). This is expected because $J_{b}^{*}$ is calculated from the APEF accumulated in this wave that is about to break. As a consequence, $\gamma=0.25$ is on average larger than the values found in Fig. 4. This relatively high $\gamma$ value implies that this overturning structure is relatively young and has a relatively high potential for mixing (it has not yet transferred its potential energy into TKE). Since some potential energy stored in the overturn may not be completely released upon breaking, this feature is an example of a situation where it is likely that $\gamma>\Gamma$ (Smyth et al. 2001).

Figure 6 is an example of the rapid cooling phase around $\phi \sim 0$ day. This 4-h time series is characterized by a sharp front passage. Strong turbulence is observed, with $\langle\varepsilon\rangle \approx 4 \times 10^{-7} \mathrm{~W} \mathrm{~kg}^{-1}$, and the mixing potential is high with $\gamma=0.59$. After the front passage, many smallscale temperature fluctuations are visible in the water column, which suggest small-scale secondary instabilities (see in Fig. 6a that light- and dark-blue contours are dominated with small-scale features compared to the yellow and orange ones). Rapid vertical fluctuations of the isopycnals over the whole water column are also visible after about 2230 UTC, also suggesting secondary instabilities and possible overturning motions in the wake of the bore. Such instabilities are consistent with the Reynolds number $\left[\mathrm{Re} \sim O\left(10^{7}\right)\right]$ involved here (Geyer et al. 2010; Mashayek and Peltier 2012a,b; Thorpe 2012).

Visual inspection of the entire dataset suggests that what was just described as a shoaling internal bore 

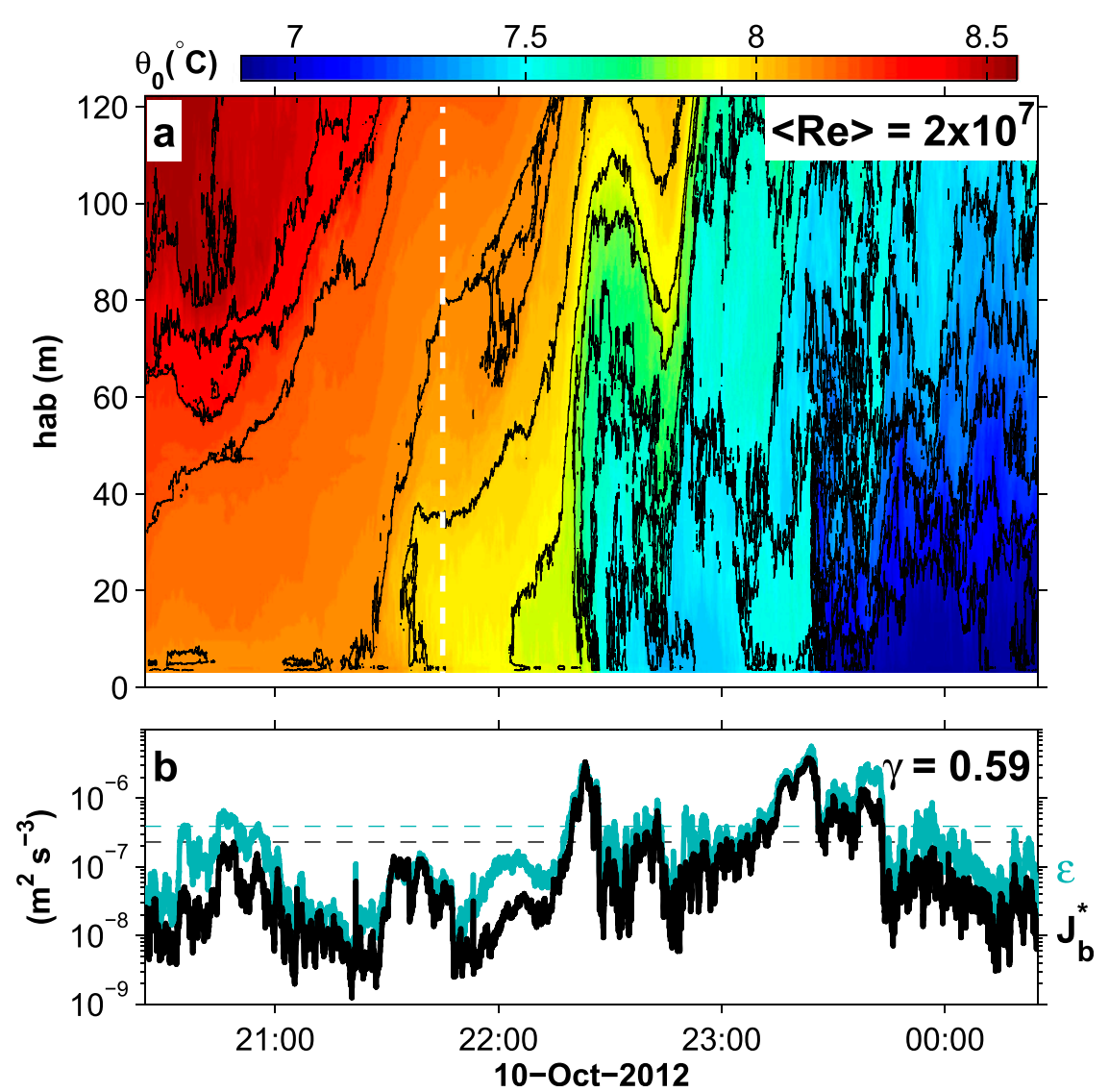

FIG. 6. The 4-h snapshot of the temperature time-depth series and vertically averaged turbulence variables starting at 2025 UTC 10 Oct 2012. This period corresponds to the tidal front passage. (a) Temperature. Isotherms (black lines) are separated by $0.1^{\circ} \mathrm{C}$ temperature increments. The white dashed vertical line corresponds to $\phi=0$. (b) As in Figs. 4 and 5, but with the average \langle\rangle over the 4 -h window.

during the transition from down- to upslope flows (Fig. 6) is typical of this phase of the diurnal tidal cycle (see all transitions observed during the 9-day mooring deployment in Fig. 7). This tidal phase is always characterized by rapid warm-to-cold transitions often accompanied with what resembles vertical plumes of fluid ejected from the bottom layer, whether by shear or buoyant instabilities. Time evolution of $\gamma$ calculated from a moving 40-min window (white lines in Fig. 7) over 6-h time series suggest that the highest values are generally found during the front passage. Compared to the other tidal phases, averaged $\langle\gamma\rangle$ ratios are relatively high during this phase $(\gamma \in[0.28,0.48]$; Fig. 8$)$, suggesting relatively young turbulence. Note that it has been verified that these high $\gamma$ values are not predominantly driven by low stratification values (through $\gamma=\left\langle J_{b}^{*}\right\rangle /\langle\varepsilon\rangle \simeq\langle\xi\rangle /\left\langle 0.64 L_{T}^{2} N^{2}\right\rangle$ ) but are rather found at any $N$ value (not shown).

To better address the phase dependence of $\gamma$, the time series of individual estimates (40-min window) are plotted in Fig. 8a. It is clear that $\gamma$ varies within a diurnal tidal cycle, with the highest values found during the bore passage (shaded areas), although other significant peaks are found elsewhere. To study the difference between the bore propagation phase and the other tidal phases, statistics of single (40-min window) estimates are presented in Figs. 8b and 8c, respectively, for the 6-h period encompassing the bore propagation (gray shades in Fig. 8a) and for the rest of the tidal cycle, respectively. Important differences are found. For example, about $90 \%$ of measurements in Fig. $8 \mathrm{~b}$ are above $\gamma=0.2$ (thick dashed line), while about $60 \%$ are below in Fig. 8 c. Moreover, $16 \%$ of the values are equal to or above $\gamma=0.55$ in Fig. $8 b$, while such high values are never found outside the bore propagation phase (Fig. 8c). On average, $\langle\gamma\rangle=0.36 \pm 0.02$ (median $\mu_{1 / 2}=0.32$ ) and $\langle\gamma\rangle=0.20 \pm 0.01$ (median $\mu_{1 / 2}=$ 0.18 ) for the bore propagation phase and the rest of the diurnal cycle, respectively. Uncertainties on average values are bootstrapped $95 \%$ confidence intervals. Recalling that $\gamma$ may be an indication of the age of turbulence, Fig. 8 

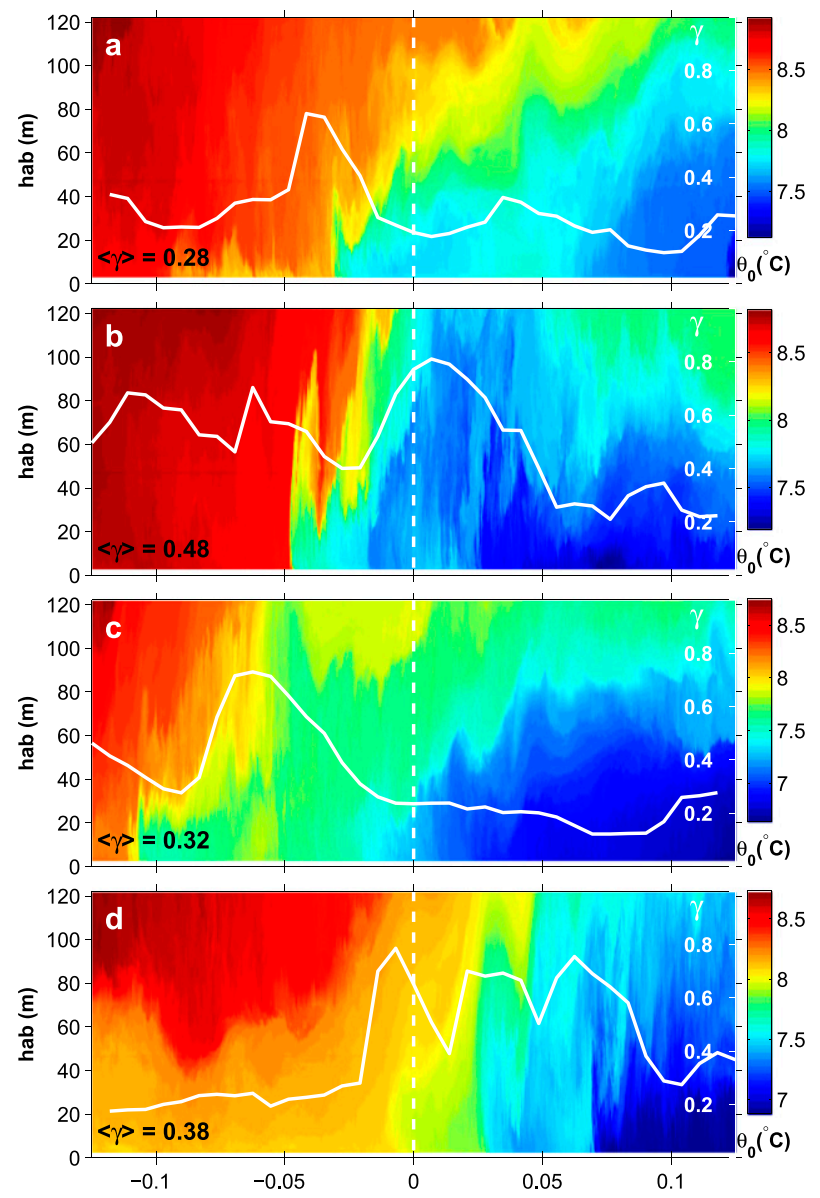
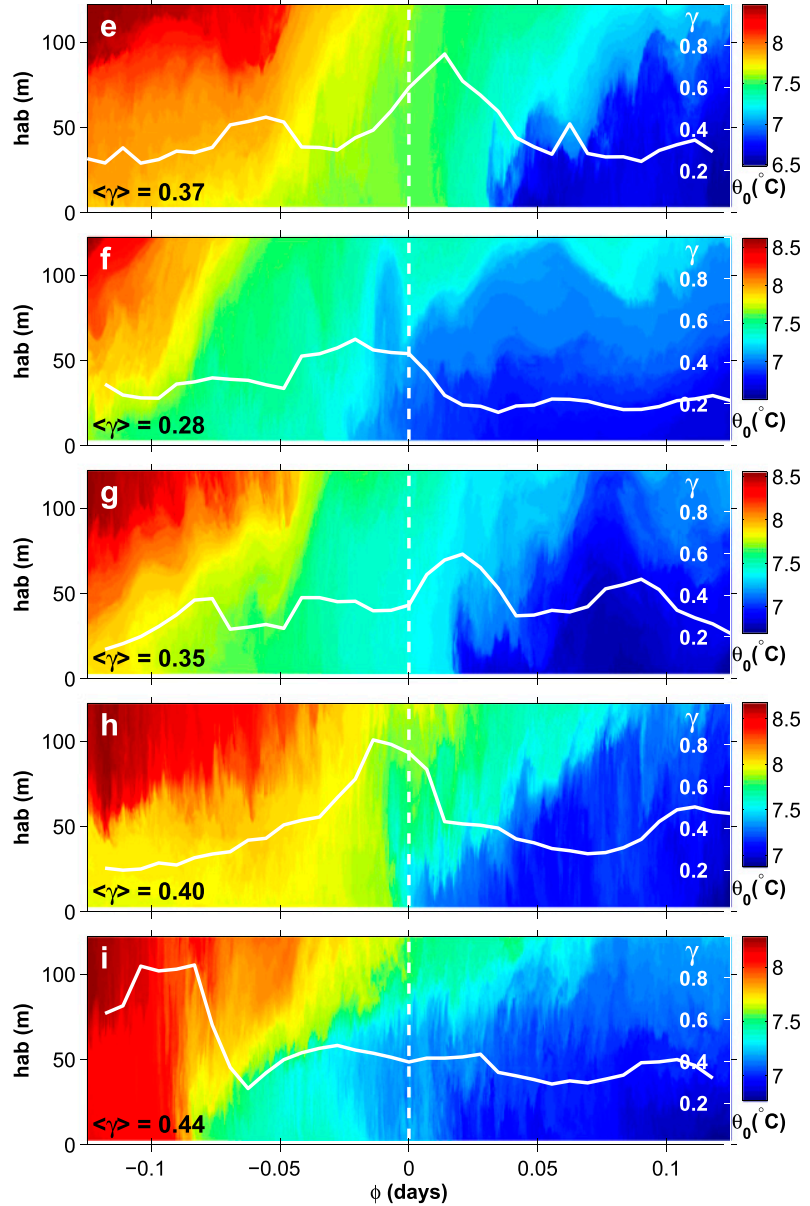

FIG. 7. Nine consecutive events of the upslope-propagating bore. Each time-depth series of the temperature correspond to a 6-h snapshot around the maximum cross-isobath velocities $(\phi=0)$. The timing of the $\phi=0$ phase for each plot are respectively (a) 2122 UTC 7 Oct 2012; (b) 2145 UTC 8 Oct 2012; (c) 2315 UTC 9 Oct 2012; (d) 2144 UTC 10 Oct 2012; (e) 0022 UTC 12 Oct 2012; (f) 0044 UTC 13 Oct 2012; (g) 0044 UTC 14 Oct 2012; (h) 0022 UTC 15 Oct 2012; and (i) 0259 UTC 16 Oct 2012. Superimposed white dashed lines for all panels represent the time evolution of $\gamma=\left\langle J_{b}^{*}\right\rangle /\langle\varepsilon\rangle$, with \langle\rangle being a 40-min and overlapping moving average window (shifted every 10 min). Averaged values over each 6-h period $\langle\gamma\rangle$ are also presented for each subplot.

shows prevailing conditions for young turbulence during the cooling phase associated with upslope bore propagation. The next section aims to give an explanation for this.

\section{On bore formation causing buoyant instabilities}

Resonant anticyclonic barotropic waves are traveling around Rockall Bank at a diurnal frequency. Such waves are best described as either topographic Rossby or double Kelvin waves, having a wavelength of about $\sim 300 \mathrm{~km}$, that is, matching the size of the bank (Longuet-Higgins 1969; Huthnance 1974; Pingree and Griffiths 1984). Moreover, the interaction of these barotropic waves with the stratification and the sloping topography gives birth to a second class of internal baroclinic motions that are also trapped to the topography (e.g., Rhines 1970; van
Haren et al. 2014). This is because the forcing frequency $\omega$ is diurnal and thus smaller than the Coriolis frequency $f$ (trapping occurs when $\omega<f$ ). It follows from this argumentation that the energy of the trapped tidal waves must be dissipated near the bank. One mechanism is likely by nonlinear evolution of the trapped wave toward large $(>100 \mathrm{~m})$ shoaling bores occurring at a diurnal frequency (Fig. 7).

It is important to note that bore generation presented in this study cannot be associated with the criticality of the slope angle versus the angle of internal wave rays. This is because internal waves are trapped and have no tidal rays. This study is thus part of a growing body of evidence suggesting that slopes matching the critical angle of internal tide rays are not required for the generation of upslope-propagating bores. Recent work rather suggests that the steepness of the slope is more 

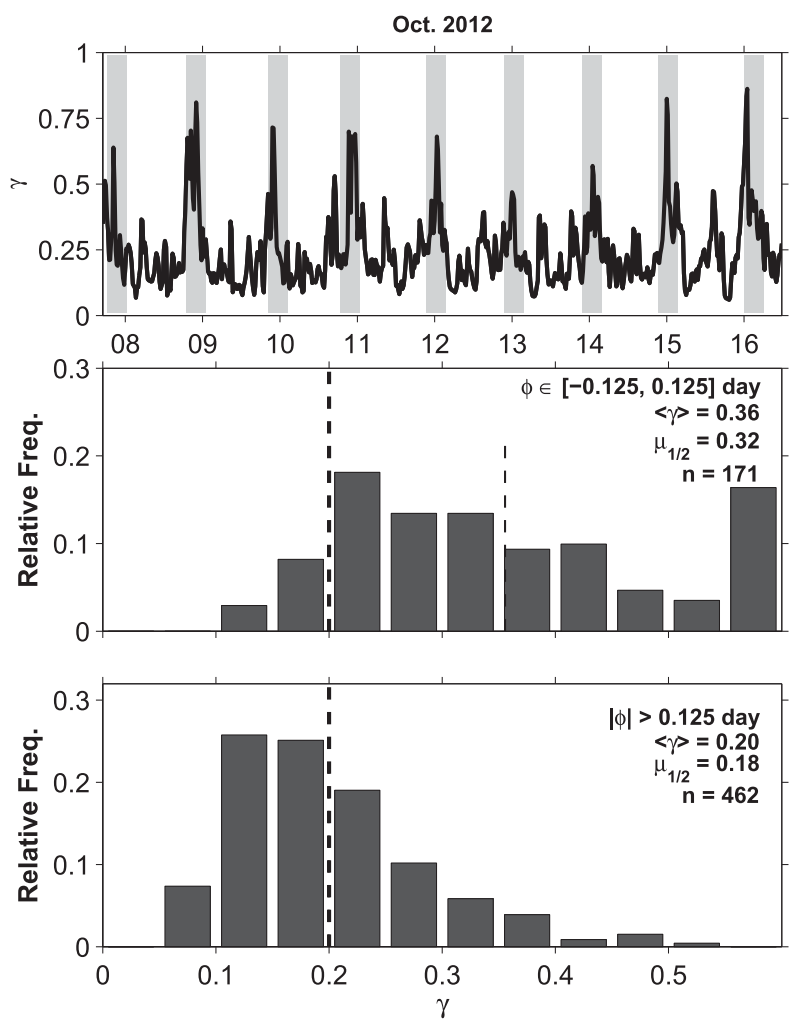

FIG. 8. Time evolution and statistics of $\gamma=\left\langle J_{b}^{*}\right\rangle /\langle\varepsilon\rangle$, with \langle\rangle being a $40-$ min and $50 \%$ overlapping moving average window. (a) Time evolution of $\gamma$ for the whole mooring deployment. Gray shades correspond to the timing of the nine subplots of Fig. 7, that is, corresponding to the upslope motion (front passage $\pm 3 \mathrm{~h}$, or $\phi \in[-0.125,0.125]$ day). Histogram distribution of $\gamma$ for (b) the upslope motions $(\phi \in[-0.125,0.125]$ day $)$ and (c) for the rest of the time series $(|\phi|>0.125$ day). The last distribution class (rightmost bar of each panel) groups all values $\gamma>0.55$. Mean $\langle\gamma\rangle$ and median $\mu_{1 / 2}$ values are given for each panel ( $\mathrm{n}$ is the number of estimates used for calculation). Mean values for each phase are also reported as thin vertical dashed lines, while $\gamma=0.2$ is indicated with a thick dashed line.

important [see van Haren (2005), Dale and Inall (2015), and van Haren et al. (2015) for bore generation at supercritical angles].

After comparing both the temperature time series (not shown) and the near-bottom velocities, we have decided that the maximum upslope current best described the arrival of the bore (indicated by the vertical dashed lines in Fig. 7). Although the periodicity of these bores is clearly diurnal-like, they are not exactly phase locked, or at least the timing of the maximum upslope currents (dashed lines) is not always consistent with the arrival of the bore from the temperature field (Fig. 7). The explanation for this lag, as well as the exact generation mechanism of these bores, is beyond the scope of this study.

The mixing potential of these bores is high. Here, forced overturning motions are associated with their passage, causing buoyant anomalies (or statically unstable flow) characterized with high $\gamma$ values (Figs. 6, 7, and 8). Because of these buoyant anomalies, convective secondary instabilities may occur. These are suggested, for example, by vertical ejection of fluid from the leading edge of the bore (two clear events are found in Fig. $7 \mathrm{f}$ and $7 \mathrm{~h}$ between 50 and $100 \mathrm{~m}$ hab, just before $\phi=0$ ). The $\sim 100 \mathrm{~m}$ density inversions populated by smallerscale inversions found in Fig. 7b (just after $\phi=0$ ) also suggest secondary convective instabilities. The fact that relatively high Richardson numbers $(\mathrm{Ri} \geq 1 / 4)$ are generally found in the wake of the front (not shown) also suggests that convective rather than shear-induced mixing may be at work.

In numerical models, such convective instabilities are found, for example, during internal wave breaking over a slope, driven by 3D density overturns (Gayen and Sarkar 2010, 2011). At sufficiently high Reynolds numbers $(\operatorname{Re}>900)$, but still far below what we observe here $\left(\operatorname{Re} \sim 10^{7}\right)$, secondary instabilities of convective nature were also identified in other numerical studies focusing on Kelvin-Helmholtz instabilities (Klaassen and Peltier 1985; Mashayek and Peltier 2011, 2012a,b). Recent work suggests higher mixing efficiencies $(\Gamma \in[0.25,1])$ when the flow is populated with such convective instabilities (Mashayek and Peltier 2013). This is because convection is known for being a much more efficient mixing mechanism than shear-driven turbulence: for pure RayleighTaylor convection $\Gamma \simeq 1$ (Dalziel et al. 2008; Gayen et al. 2013). In other recent numerical work on large convective overturning events, that is, cases that have some resemblance to that presented here, Chalamalla and Sarkar (2015) found $\Gamma \in[0.67,1]$, which is also close to the mixing efficiency of pure convection. For breaking waves such as those observed here, small-scale convectivelike structures occur because of potential energy anomalies (density inversions) created during the overturning motions. We can thus expect the mixing to be highly efficient during the bore propagation phase.

\section{On the apparent mixing efficiency of turbulence above sloping topography}

Because of measurement difficulties, estimations of mixing efficiency in the ocean (e.g., $\Gamma$ ) are generally rare in the literature [see Oakey (1982) for pioneer work]. These difficulties lie in the fact that turbulence is generally intermittent (the stationary hypothesis needed to compute $\Gamma$ does not hold) and that separating reversible and nonreversible density fluctuations is complex, making any estimation of $J_{b}$ difficult (Bouffard et al. 2013). This question was addressed in numerical (Slinn and Riley 1996, 1998; Umlauf and Burchard 2011; Mashayek 
and Peltier 2013) and laboratory studies (Ivey and Nokes 1989) but also from in situ measurements (van Haren et al. 1994; Davis and Monismith 2011; Dunckley et al. 2012; Walter et al. 2014).

Measurements presented here do not allow a direct estimation of $\Gamma$ because they suffer from the two limitations mentioned above, that is, the difficulty of ensuring stationarity and separating irreversible from reversible density fluctuations. We are thus not able to directly address the question of mixing efficiency. However, our measurements, in addition to offering a unique high spatial $(\sim 1 \mathrm{~m})$ and temporal $(\sim 1 \mathrm{~s})$ resolution that is hardly reached with standard observational methods, have some similarities with recent numerical and laboratory results, which is worth noting.

Our approach is to use a more traditional method in addressing the dissipation rate of TKE and the buoyancy fluxes from the finescale structure. The hypotheses and limitations of this method are exposed in section 3 . Within the limit of validity of these assumptions (i.e., if one accepts that $\gamma \sim \Gamma$ on a phase average sense), our results suggest that mixing occurring during the rapid upslope propagation of the internal bore is more efficient than during the other phases of the diurnal cycle (gray shades in Fig. 8a). Indeed, for this phase, corresponding to the $\pm 3 \mathrm{~h}$ centered on bore passages, we calculated $\langle\gamma\rangle=0.36 \pm 0.02$, on average, compared to $\gamma_{\text {rest }}=0.20 \pm 0.01$ for the rest of the diurnal cycle (Figs. 8b and 8c, respectively). While it is probably more reasonable to take these estimates as upper bounds for the flux coefficient $(\gamma \geq \Gamma$; see section 3), this neartwofold change in $\gamma$ may suggest an increase in mixing efficiencies during this particular phase of the diurnal tidal cycle. This hypothesis would need to be verified with more field work that includes microstructure profiler measurements.

However, $\gamma$ estimates presented here are comparable with other flux coefficient estimates that can be found in the literature for similar contexts. For example, $\Gamma \in$ $[0.25,0.5]$ were observed in laboratory and numerical studies of breaking internal waves (Ivey and Nokes 1989; Slinn and Riley 1996, 1998). From field work, high mixing efficiencies $(\Gamma \in[0.13-0.5])$ were also found by van Haren et al. (1994). These values were observed from direct microstructure measurements of $\varepsilon$ and $J_{b}$ above an ocean sloping bottom with a smaller slope angle (3\%). The fact that in our observations the water column is still stratified a few meters above the bottom also points at efficient mixing. The sloping topography thus plays an important role in restratifying the water column near the seabed after mixing operates.

It is worth noting that the present buoyancy Reynolds numbers $\left[\operatorname{Re}_{b}=\varepsilon /\left(\nu N^{2}\right)\right]$ are generally high $\left(\operatorname{Re}_{b}>10^{3}\right.$ for $97 \%$ of the data, with about $80 \%$ in the $\left[5 \times 10^{3}, 5 \times\right.$ $\left.10^{5}\right]$ range, not shown). Recent studies, however, suggest significantly reduced mixing efficiencies $(\Gamma \ll 0.2)$ when $\mathrm{Re}_{b} \geq 100$ (Shih et al. 2005; Davis and Monismith 2011; Dunckley et al. 2012; Bouffard et al. 2013; Walter et al. 2014). Our observations may thus highlight a specific case of efficient mixing that occurs during internal wave breaking on deep sloping topography, when the breaking is associated with high available potential energy.

\section{Conclusions}

A mooring deployed in the Rockall Bank area shows that diurnal variations of currents above a deep slope can be described as rapid upslope-propagating pulses followed by slower downslope motions. The transition from down- to upslope flows occurs abruptly in what resembles shoaling bores or breaking internal waves. High-resolution temperature observations demonstrate that these bores generate small-scale overturning/ convective motions that may be associated with secondary instabilities. The imbalance between the dissipation rate of TKE and the rate of disappearance of available potential energy for mixing suggests that observed instabilities are relatively young (growing turbulence), making this phase relatively important for the global mixing budget at this site.

The generation mechanism of the borelike tidal front, responsible for the asymmetry between the upslope and downslope flows is unclear. The shape of the incoming tidal fronts (steep isopycnals) suggests that they are driven by strong nonlinearities. The mechanisms converting the linear forcing (from the trapped barotropic tidal wave) to this asymmetric and steep front deserve more investigation, but the steepness of the bank in this area may be responsible for driving it to a near-breaking state.

It is also suggested that the mixing potential $\gamma$ is higher during the tidal phase characterizing the propagation of the tidal bore. This increase of $\gamma$ is the result of secondary instabilities, visible as small-scale density inversions. The higher $\gamma$ observed during the upslope phase is also coincident with lower $N$ by about a factor of 2 , on average (although $\varepsilon$ is highest). This is counterintuitive since we would expect decreasing mixing efficiency with decreasing stratification. It is thus likely that the buoyancy anomalies, likely generated by secondary convective instabilities, overcome the reduction of stratification over this specific phase of the tidal cycle.

Acknowledgments. The authors thank the captain and crew of the R/V Pelagia, M. Laan for all his work on thermistors, three anonymous reviewers for their valuable 
comments, and A. Cimatoribus for the many fruitful discussions about this topic. This work has been financed by the Netherlands Organization for Scientific Research (NWO) and by the Fonds de recherche du QuébecNature et technologies through a postdoctoral fellowship to F. Cyr.

\section{REFERENCES}

Armi, L., 1978: Some evidence of boundary mixing in the deep ocean. J. Geophys. Res., 83, 1971-1979, doi:10.1029/JC083iC04p01971.

Bouffard, D., J. D. Ackerman, and L. Boegman, 2013: Factors affecting the development and dynamics of hypoxia in a large shallow stratified lake: Hourly to seasonal patterns. Water Resour. Res., 49, 2380-2394, doi:10.1002/wrcr.20241.

Chalamalla, V. K., and S. Sarkar, 2015: Mixing, dissipation rate, and their overturn-based estimates in a near-bottom turbulent flow driven by internal tides. J. Phys. Oceanogr., 45, 19691987, doi:10.1175/JPO-D-14-0057.1.

Crawford, W. R., 1986: A comparison of length scales and decay times of turbulence in stably stratified flows. J. Phys. Oceanogr., 16, 1847-1854, doi:10.1175/1520-0485(1986)016<1847: ACOLSA $>2.0 . \mathrm{CO} ; 2$.

Dale, A. C., and M. E. Inall, 2015: Tidal mixing processes amid small-scale, deep-ocean topography. Geophys. Res. Lett., 42, 484-491, doi:10.1002/2014GL062755.

Dalziel, S. B., M. D. Patterson, C. P. Caulfield, and I. A. Coomaraswamy, 2008: Mixing efficiency in high-aspectratio Rayleigh-Taylor experiments. Phys. Fluids, 20, 065106, doi:10.1063/1.2936311.

Davis, K. A., and S. G. Monismith, 2011: The modification of bottom boundary layer turbulence and mixing by internal waves shoaling on a barrier reef. J. Phys. Oceanogr., 41, 22232241, doi:10.1175/2011JPO4344.1.

Dillon, T. M., 1982: Vertical overturns: A comparison of Thorpe and Ozmidov length scales. J. Geophys. Res., 87, 9601-9613, doi:10.1029/JC087iC12p09601.

_ 1984: The energetics of overturning structures: Implications for the theory of fossil turbulence. J. Phys. Oceanogr., 14, 541549, doi:10.1175/1520-0485(1984)014<0541:TEOOSI >2.0.CO;2.

—_, and M. M. Park, 1987: The available potential energy of overturns as an indicator of mixing in the seasonal thermocline. J. Geophys. Res., 92, 5345-5353, doi:10.1029/JC092iC05p05345.

Dunckley, J. F., J. R. Koseff, J. V. Steinbuck, S. G. Monismith, and A. Genin, 2012: Comparison of mixing efficiency and vertical diffusivity models from temperature microstructure. J. Geophys. Res., 117, C10008, doi:10.1029/2012JC007967.

Ferron, B., H. Mercier, K. Speer, A. Gargett, and K. Polzin, 1998: Mixing in the Romanche fracture zone. J. Phys. Oceanogr., 28, 19291945, doi:10.1175/1520-0485(1998)028<1929:MITRFZ>2.0.CO;2.

Galbraith, P. S., 1992: Relating overturns to mixing and buoyancy flux. Ph.D. thesis, Dalhousie University, $242 \mathrm{pp}$.

— files. J. Atmos. Oceanic Technol., 13, 688-702, doi:10.1175/ 1520-0426(1996)013<0688:IOICP>2.0.CO;2.

Garrett, C., and E. Kunze, 2007: Internal tide generation in the deep ocean. Annu. Rev. Fluid Mech., 39, 57-87, doi:10.1146/ annurev.fluid.39.050905.110227.

Gayen, B., and S. Sarkar, 2010: Turbulence during the generation of internal tide on a critical slope. Phys. Rev. Lett., 104, 218502, doi:10.1103/PhysRevLett.104.218502.
— and - 2011: Boundary mixing by density overturns in an internal tidal beam. Geophys. Res. Lett., 38, L14608, doi:10.1029/ 2011 GL048135.

—_ G. O. Hughes, and R. W. Griffiths, 2013: Completing the mechanical energy pathways in turbulent Rayleigh-Bénard convection. Phys. Rev. Lett., 111, 124301, doi:10.1103/ PhysRevLett.111.124301.

Geyer, W. R., A. C. Lavery, M. E. Scully, and J. H. Trowbridge, 2010: Mixing by shear instability at high Reynolds number. Geophys. Res. Lett., 37, L22607, doi:10.1029/2010GL045272.

Howard, L. N., 1961: Note on a paper of John W. Miles. J. Fluid Mech., 10, 509-512, doi:10.1017/S0022112061000317.

Huthnance, J., 1974: On the diurnal tidal currents over Rockall Bank. Deep-Sea Res. Oceanogr. Abstr., 21, 23-35, doi:10.1016/ 0011-7471(74)90016-3.

Itsweire, E. C., K. N. Helland, and C. W. van Atta, 1986: The evolution of grid-generated turbulence in a stably stratified fluid. J. Fluid Mech., 162, 299-338, doi:10.1017/S0022112086002069.

Ivey, G., and R. I. Nokes, 1989: Vertical mixing due to the breaking of critical internal waves on sloping boundaries. J. Fluid Mech., 204, 479-500, doi:10.1017/S0022112089001849.

Jayne, S. R., and L. C. St. Laurent, 2001: Parameterizing tidal dissipation over rough topography. Geophys. Res. Lett., 28 , 811-814, doi:10.1029/2000GL012044.

Klaassen, G. P., and W. R. Peltier, 1985: The onset of turbulence in finite-amplitude Kelvin-Helmholtz billows. J. Fluid Mech., 155, 1-35, doi:10.1017/S0022112085001690.

Ledwell, J., E. Montgomery, K. Polzin, L. C. St. Laurent, R. Schmitt, and J. Toole, 2000: Evidence for enhanced mixing over rough topography in the abyssal ocean. Nature, 403, 179182, doi:10.1038/35003164.

Longuet-Higgins, M. S., 1969: On the trapping of long-period waves round islands. J. Fluid Mech., 37, 773-784, doi:10.1017/ S0022112069000875.

Mashayek, A., and W. R. Peltier, 2011: Three-dimensionalization of the stratified mixing layer at high Reynolds number. Phys. Fluids, 23, 111701, doi:10.1063/1.3651269.

_ cursory to stratified shear flow transition. Part 1 Shear aligned convection, pairing, and braid instabilities. J. Fluid Mech., 708, 5-44, doi:10.1017/jfm.2012.304.

— cursory to stratified shear flow transition. Part 2 The influence of stratification. J. Fluid Mech., 708, 45-70, doi:10.1017/ jfm.2012.294.

— Does the route to turbulence matter to its efficiency? J. Fluid Mech., 725, 216-261, doi:10.1017/jfm.2013.176.

Mater, B. D., S. M. Schaad, and S. K. Venayagamoorthy, 2013: Relevance of the Thorpe length scale in stably stratified turbulence. Phys. Fluids, 25, 076604, doi:10.1063/1.4813809.

_ S. K. Venayagamoorthy, L. S. Laurent, and J. N. Moum, 2015: Biases in Thorpe scale estimates of turbulence dissipation. Part I: Assessments from large-scale overturns in oceanographic data. J. Phys. Oceanogr., 45, 2497-2521, doi:10.1175/ JPO-D-14-0128.1.

Miles, J. W., 1961: On the stability of heterogeneous shear flows. J. Fluid Mech., 10, 496-508, doi:10.1017/S0022112061000305.

Oakey, N. S., 1982: Determination of the rate of dissipation of turbulent energy from simultaneous temperature and velocity shear microstructure measurements. J. Phys. Oceanogr., 12, 256-271, doi:10.1175/1520-0485(1982)012<0256: DOTROD $>2.0 . \mathrm{CO} ; 2$. 
Pingree, R. D., and D. K. Griffiths, 1984: Trapped diurnal waves on Porcupine and Rockall Banks. J. Mar. Biol. Assoc. U. K., 64, 889-897, doi:10.1017/S0025315400047305.

Polzin, K., J. Toole, J. Ledwell, and R. Schmitt, 1997: Spatial variability of turbulent mixing in the abyssal ocean. Science, 276, 93-96, doi:10.1126/science.276.5309.93.

Rhines, P., 1970: Edge-, bottom-, and Rossby waves in a rotating stratified fluid. Geophys. Fluid Dyn., 1, 273-302, doi:10.1080/ 03091927009365776.

Rudnick, D., and Coauthors, 2003: From tides to mixing along the Hawaiian Ridge. Science, 301, 355-357, doi:10.1126/ science. 1085837.

Seim, H. E., and M. C. Gregg, 1994: Detailed observations of a naturally occurring shear instability. J. Geophys. Res., 99, 10 049-10 073, doi:10.1029/94JC00168.

Shih, L. H., J. R. Koseff, G. N. Ivey, and J. H. Ferziger, 2005: Parameterization of turbulent fluxes and scales using homogeneous sheared stably stratified turbulence simulations. J. Fluid Mech., 525, 193-214, doi:10.1017/ S0022112004002587.

Slinn, D. N., and J. J. Riley, 1996: Turbulent mixing in the oceanic boundary layer caused by internal wave reflection from sloping terrain. Dyn. Atmos. Oceans, 24, 51-62, doi:10.1016/ 0377-0265(95)00425-4.

— and — 1998: Turbulent dynamics of a critically reflecting internal gravity wave. Theor. Comput. Fluid Dyn., 11, 281-303, doi:10.1007/s001620050094.

Smyth, W. D., J. N. Moum, and D. R. Caldwell, 2001: The efficiency of mixing in turbulent patches: Inferences from direct simulations and microstructure observations. J. Phys. Oceanogr., 31, 1969-1992, doi:10.1175/1520-0485(2001)031<1969: TEOMIT>2.0.CO;2.

Stansfield, K., C. Garrett, and R. K. Dewey, 2001: The probability distribution of the Thorpe displacement within overturns in Juan de Fuca Strait. J. Phys. Oceanogr., 31, 3421-3434, doi:10.1175/ 1520-0485(2001)031<3421:TPDOTT>2.0.CO;2.

Stillinger, K. N., K. N. Helland, and C. W. van Atta, 1983: Experiments on the transition of homogeneous turbulence to internal waves in a stratified fluid. J. Fluid Mech., 131, 91-122, doi:10.1017/S0022112083001251.

St. Laurent, L., and C. Garrett, 2002: The role of internal tides in mixing the deep ocean. J. Phys. Oceanogr., 32, 2882-2899, doi:10.1175/1520-0485(2002)032<2882:TROITI >2.0.CO;2.

Thorpe, S. A., 1977: Turbulence and mixing in a Scottish loch. Philos. Trans. Roy. Soc., A286, 125-181, doi:10.1098/ rsta.1977.0112.

_ 2012: On the Kelvin-Helmholtz route to turbulence. J. Fluid Mech., 708, 1-4, doi:10.1017/jfm.2012.383.
Umlauf, L., and H. Burchard, 2011: Diapycnal transport and mixing efficiency in stratified boundary layers near sloping topography. J. Phys. Oceanogr., 41, 329-346, doi:10.1175/2010JPO4438.1.

van Haren, H., 2005: Details of stratification in a sloping bottom boundary layer of Great Meteor Seamount. Geophys. Res. Lett., 32, L07606, doi:10.1029/2004GL022298.

_ N. S. Oakey, and C. Garrett, 1994: Measurements of internal wave band eddy fluxes above a sloping bottom. J. Mar. Res., 52, 909-946, doi:10.1357/0022240943076876.

_- M. Laan, D.-J. Buijsman, L. Gostiaux, M. G. Smit, and E. Keijzer, 2009: NIOZ3: Independent temperature sensors sampling yearlong data at a rate of $1 \mathrm{~Hz}$. IEEE J. Oceanic Eng., 34, 315-322, doi:10.1109/JOE.2009.2021237.

— - E. Morozov, L. Gostiaux, and R. Tarakanov, 2013: Convective and shear-induced turbulence in the deep Kane Gap. J. Geophys. Res. Oceans, 118, 5924-5930, doi:10.1002/2013JC009282.

_, F. Mienis, G. C. A. Duineveld, and M. S. S. Lavaleye, 2014: Highresolution temperature observations of a trapped nonlinear diurnal tide influencing cold-water corals on the Logachev mounds. Prog. Oceanogr., 125, 16-25, doi:10.1016/j.pocean.2014.04.021.

- A. Cimatoribus, and L. Gostiaux, 2015: Where large deepocean waves break. Geophys. Res. Lett., 42, 2351-2357, doi:10.1002/2015GL063329.

Walter, R. K., M. E. Squibb, C. B. Woodson, J. R. Koseff, and S. G. Monismith, 2014: Stratified turbulence in the nearshore coastal ocean: Dynamics and evolution in the presence of internal bores. J. Geophys. Res. Oceans, 19, 8709-8730, doi:10.1002/ 2014JC010396.

Waterhouse, A. F., and Coauthors, 2014: Global patterns of diapycnal mixing from measurements of the turbulent dissipation rate. J. Phys. Oceanogr., 44, 1854-1872, doi:10.1175/ JPO-D-13-0104.1.

Wesson, J. C., and M. C. Gregg, 1994: Mixing at Camarinal Sill in the Strait of Gibraltar. J. Geophys. Res., 99, 9847-9878, doi:10.1029/94JC00256.

White, M., J. M. Roberts, and T. Weering, 2007: Do bottomintensified diurnal tidal currents shape the alignment of carbonate mounds in the NE Atlantic? Geo-Mar. Lett., 27, 391-397, doi:10.1007/s00367-007-0060-8.

Wijesekera, H. W., and T. M. Dillon, 1997: Shannon entropy as an indicator of age for turbulent overturns in the oceanic thermocline. J. Geophys. Res., 102, 3279-3291, doi:10.1029/96JC03605. _, _ , and L. Padman, 1993: Some statistical and dynamical properties of turbulence in the oceanic pycnocline. J. Geophys. Res., 98, 22 665-22 679, doi:10.1029/93JC02352.

Wunsch, C., and R. Ferrari, 2004: Vertical mixing, energy, and the general circulation of the oceans. Annu. Rev. Fluid Mech., 36, 281-314, doi:10.1146/annurev.fluid.36.050802.122121. 